abnormalities in animals following recovery from early malnutrition are considered in separate papers from different groups of workers. These observations are invaluable in considering the ultimate prognosis of protein-calorie malnutrition in man.

Sir Joseph Hutchison in his closing remarks mentioned the economic and social factors which must change if human nutrition is to be improved. The ensuing discussion revealed once more that the pattern of malnutrition varies from area to area and moreover that the problems of prevention cannot be solved solely in dietary terms.

This is a valuable book, well produced and the contributions are well documented. It is a pity that it has taken over a year to be published, and there seems to be a place for using special techniques to produce proceedings of conferences quickly and cheaply. Nevertheless, the editors and Glaxo Limited are to be thanked for this useful addition to the medical literature.

\section{Les Rythmes}

Proceedings of a Conference held in Lyon, December 1967. Pp. 350, illustrated. Lyon: Simep Editions, 1968. Price not given.

This book is a collection of lectures presented at the International Symposium on Rhythm which took place in Lyon, France, in December 1967. The texts are edited by Professor P. Mounier-Kuhn and Dr J-C. Lafon of the
Institute of Audiophonology at the Lyon Faculty of Medicine. The first three sections of the book are of general interest to neurologists and physicians but particularly to those who are concerned with disorders of speech, with re-education of children and others handicapped by speech defects. I found of special interest the paper by Paul Fraisse who discusses the psychology of human rhythm, its role in child development, in human behaviour and in such activities as dancing, composing music and writing poetry. This theme is further developed by Professor B. Malmberg of Lund University, Sweden, who analyses in particular the use of rhythm or periodicity in speech, the so-called 'rythme linguistique et phonetique' phenomenon.

The biological and electrophysiological phenomena at the level of cochlear and vestibular apparatus are described in other communications and their importance explained in the auditory perception and human expression. In the section on rhythms and the child, there are papers on disturbance of rhythm in stammerers, deaf persons, in chorea, Parkinson's disease and mental deficiency. The two final sections of the book contain papers of a more philosophical nature such as the aesthetics of rhythm, rhythm in music, poetry and architecture, and an interesting comparative study of rhythm in French and Polish languages. The closing chapter is a most erudite lecture by the academician Pierre Emmanuel on the symbolism of rhythm.

The English reader would have to be more than fluent in French to enjoy reading these transactions. 